\title{
Otimização dos \\ Parâmetros de Produção do Amido de Mandioca Fermentado
}

\author{
Christiane A. Starling
}

O amido de mandioca fermentado (polvilho azedo) pode ser considerado um amido modificado química e enzimaticamente com propriedade de expansão. É produzido em pequenas indústrias, onde não existe um sistema interno de controle de qualidade dos processos e produtos. O presente trabalho teve como objetivos diagnosticar a qualidade do polvilho azedo produzido artesanalmente em municípios produtores de Goiás; avaliar experimentalmente a influência do volume do ácido lático, massa de inóculo e do tempo de fermentação sobre a característica de expansão do polvilho azedo produzido experimentalmente e comparar os resultados alcançados com parâmetros diagnosticados dos polvilhos produzidos artesanalmente.

Palavras-chave: polvilho azedo; expansão; fécula.

The fermented cassava starch (cassava starch) can be considered a chemically and enzymatically modified starch with expansion property. It is produced in small factories, where there is an internal system of quality control processes and products. This study aimed to: diagnose the quality of home made sour in producing municipalities of Goiás; evaluate experimentally the influence of the volume of lactic acid, mass of inoculum and fermentation time on characteristic expansion of cassava starch produced experimentally, and compare the results with parameters diagnosed from fermented cassava produced by craftsmen.

Keywords: sour, expansion; cassava starch. 


\section{Introdução}

O Brasil é um dos maiores produtores mundiais de mandioca, tendo produzido, em 2008, 26 milhões de toneladas, numa área cultivada de 1,91 milhões de hectares ${ }^{1}$. A mandioca (Manihot esculenta, Crantz) desempenha, por seu alto teor energético, um importante papel na dieta alimentar dos brasileiros. Além de ser uma das mais tradicionais culturas agrícolas brasileiras, sendo cultivada em praticamente todo o território nacional ${ }^{2}$.

A industrialização da mandioca é uma boa alternativa para agregar valor a esta cultura tradicional cujo produto possui o teor de amido em torno de $80 \%$ sobre a matéria seca ${ }^{3}$.

A mandioca é utilizada como matéria-prima nas indústrias, tendo uma grande variedade de uso, com destaque para a fécula. A fécula e seus produtos derivados têm apresentado competitividade crescente em outros mercados de produtos para a alimentação humana ou como insumos em diversos ramos industriais, tais como de papel, embalagem, cola, mineração, têxtil e farmacêutica. São nesses mercados que ocorrem as maiores oportunidades de agregação de valor e encontram-se as maiores perspectivas para o desenvolvimento da atividade mandioqueira ${ }^{4}$.

A indústria de amido vem crescendo e se aperfeiçoando, levando a necessidade de produtos com características específicas que atendam às exigências do mercado, o que possibilita o processamento de matériasprimas amiláceas ainda pouco exploradas 5 . O polvilho azedo, produto típico brasileiro e muito utilizado na culinária em geral, é obtido por fermentação natural da fécula, sendo a falta de qualidade, um dos maiores problemas no mercado de exportação .

$\mathrm{O}$ processo de globalização provoca mudanças constantes na economia brasileira obrigando as empresas a repensarem suas formas de gerenciamento. $\mathrm{O}$ setor de polvilho está inserido nesse contexto, obrigando os empresários do setor a revisarem suas práticas, bem como reduzirem custos e despesas. A busca pela eficiência no processo de produção do polvilho é, também, uma forma de sobrevivência em um cenário econômico que a cada dia se torna mais competitivo ${ }^{7}$. O polvilho azedo apresenta grande heterogeneidade na qualidade, sendo ainda um produto artesanal, mesmo quando fabricado em fecularias modernas. Sua caracterização é muito importante para tentar entender melhor os principais problemas ligados aos processos de produção e a potencialidade do uso alimentar ${ }^{8}$.
O polvilho azedo é caracterizado pelas suas propriedades físicas, químicas e reológicas, as quais são diferentes do amido nativo do qual se originou. A propriedade de expansão é uma das mais importantes características do produto, sendo um parâmetro fundamental na sua avaliação? .

Garcia e Leone ${ }^{10}$ estudando a influência da modificação química e da secagem da fécula de mandioca no processo de expansão, observaram que a concentração de ácido lático, durante processo de modificação fotoquímica, interfere no desenvolvimento da expansão, sendo que o aumento da expansão é significativo com o aumento da concentração de ácido lático.

$\mathrm{O}$ presente trabalho justifica-se pela necessidade de padronização do processo produtivo do polvilho azedo, propiciando ao segmento industrial a possibilidade de produção em larga escala, com padrão de qualidade definidos, e com a minimização dos custos operacionais.

Assim, tendo em vista a otimização dos parâmetros de produção e a padronização da qualidade do polvilho, o presente trabalho teve como objetivos diagnosticar a qualidade do polvilho azedo produzido artesanalmente em municípios produtores de Goiás; avaliar experimentalmente, por meio da metodologia de superfície de resposta, a influência do volume do ácido lático, massa de inóculo e do tempo de fermentação sobre a característica de expansão do polvilho e, finalmente, comparar os resultados alcançados com parâmetros diagnosticados dos polvilhos produzidos artesanalmente nos municípios de maior produção de Goiás.

\section{Material e Métodos}

Os ensaios e as análises foram conduzidos nos Laboratório de Alimentos e Planta Piloto do SENAI, localizados na Escola SENAI Vila Canaã, na Empresa Brasileira de Pesquisa em Agropecuária (EMPRAPAGO), nos Laboratórios do Departamento de Ciência e Tecnologia de Alimentos da Universidade Estadual e Londrina (DCTA/UEL), no Centro de Raízes e Amidos Tropicais (CERAT/Botucatu) da Universidade Estadual Paulista e no Laboratório de Controle de Qualidade de Alimentos (LCQA) da Faculdade de Farmácia (UFG-GO). 


\section{METODOLOGIA DO DIAGNÓSTICO}

Para coleta dos dados, foram utilizadas as técnicas de investigação quantitativas e qualitativas, como a realização de entrevistas e observação assistemática ${ }^{11}$.

\section{MATERIAL}

\section{Matéria-prima}

As amostras de fécula de mandioca foram provenientes da Indústria FEBELA- Fecularia Bela Vista LTDA, localizada no município de Bela Vista no Estado de Goiás, da safra de 2009, cultivar Branca de Santa Catarina. Até a realização do ensaio, a fécula foi mantida em embalagem original (sacos em polietileno de alta densidade de $25 \mathrm{~kg}$ ), estocados à temperatura ambiente, sob estrados.

A fécula de mandioca foi analisada quanto aos parâmetros: teor de amido, amilose; amilopectina; expansão; índice de absorção de água; $\mathrm{pH}$; acidez titulável, umidade e contagem total de mesófilos. As análises de amido foram realizadas segundo Rickard; Behn ${ }^{12}$ e demais parâmetros físico-químicos seguiram metodologia do Instituto Adolfo Lutz $^{13}$. O índice de absorção de água foi determinado, segundo metodologia proposta por $\mathrm{Cereda}^{14}$ e o de expansão, segundo metodologia proposta por Pereira et al. ${ }^{15}$. A avaliação microbiana foi realizada, segundo metodologia oficial da American Public Health Association ${ }^{16}$.

\section{Insumos}

O ácido lático utilizado no ensaio foi da marca Synth ${ }$, P.A., concentração de $85 \%$ e densidade de $1,206 \mathrm{~g} / \mathrm{mL}$.

\section{Inóculo}

O inóculo foi preparado utilizando a fécula de mandioca e água, sendo esse deixado para fermentar por 10 dias.

\section{DESENVOLVIMENTO EXPERIMENTAL}

$\mathrm{O}$ ensaio foi conduzido conforme delineamento central composto rotacional (DCCR) com 3 fatores ou variáveis independentes. Foi realizado um ensaio fatorial ${ }^{23} \mathrm{com}$ cinco pontos centrais e seis pontos axiais, totalizando 19 experimentos. Estudou-se o efeito das três variáveis independentes: volume de ácido láctico (X1), massa de inóculo (X2) e tempo de fermentação em horas (X3) sob a variável resposta, expansão do polvilho obtido (Y), expostos na Tabela 1 e o delineamento completo na Tabela 2.
Tabela 1. Níveis das variáveis: volume de ácido lático, massa de inoculo e tempo de fermentação do fatorial $23 \mathrm{com}$ seis pontos centrais e seis axiais.

\begin{tabular}{|c|c|c|c|c|c|c|}
\hline \multicolumn{2}{|c|}{ Variáveis } & \multicolumn{5}{|c|}{ Níveis } \\
\cline { 3 - 7 } & $\mathbf{- 1 , 6 8}$ & $\mathbf{- 1}$ & $\mathbf{0}$ & $\mathbf{+ 1}$ & $\mathbf{+ 1 , 6 8}$ \\
\hline $\begin{array}{c}\text { Volume de } \\
\text { ácido lático } \\
(\mathrm{mL})\end{array}$ & $\mathrm{X} 1$ & 0,00 & 6,00 & 15,00 & 24,00 & 30,00 \\
\hline $\begin{array}{c}\text { Massa de } \\
\text { Inoculo (g) }\end{array}$ & $\mathrm{X} 2$ & 0,00 & 15,20 & 37,50 & 59,80 & 75,00 \\
\hline $\begin{array}{c}\text { Tempo de } \\
\text { fermentação } \\
(\mathrm{h})\end{array}$ & $\mathrm{X} 3$ & 7,68 & 24,00 & 48,00 & 72,00 & 88,32 \\
\hline
\end{tabular}

Tabela 2. Planejamento Fatorial $2^{3} \mathrm{com}$ seis pontos centrais e seis axiais sendo as variáveis reais: volume de ácido lático, massa de inóculo e tempo de fermentação.

\begin{tabular}{|c|c|c|c|c|c|c|}
\hline \multirow[b]{2}{*}{ Experimento } & \multicolumn{3}{|c|}{$\begin{array}{l}\text { Variáveis } \\
\text { Codificadas }\end{array}$} & \multicolumn{3}{|c|}{ Variáveis reais } \\
\hline & $\mathrm{X} 1$ & $\mathrm{X} 2$ & $\mathrm{X} 3$ & $\begin{array}{l}\text { Acido } \\
\text { lático } \\
(\mathrm{mL})\end{array}$ & $\begin{array}{c}\text { Massa } \\
(\mathrm{g})\end{array}$ & $\begin{array}{c}\text { Tempo } \\
\text { fermentação } \\
\text { (h) }\end{array}$ \\
\hline 1 & -1 & -1 & -1 & 6 & 15,2 & 24 \\
\hline 2 & 1 & -1 & -1 & 24 & 15,2 & 24 \\
\hline 3 & -1 & 1 & -1 & 6 & 59,8 & 24 \\
\hline 4 & 1 & 1 & -1 & 24 & 59,8 & 24 \\
\hline 5 & -1 & -1 & 1 & 6 & 15,2 & 72 \\
\hline 6 & 1 & -1 & 1 & 24 & 15,2 & 72 \\
\hline 7 & -1 & 1 & 1 & 6 & 59,8 & 72 \\
\hline 8 & 1 & 1 & 1 & 24 & 59,8 & 72 \\
\hline 9 & $-1,68$ & 0 & 0 & 0 & 37,5 & 48 \\
\hline 10 & 1,68 & 0 & 0 & 30 & 37,5 & 48 \\
\hline 11 & 0 & $-1,68$ & 0 & 15 & 0 & 48 \\
\hline 12 & 0 & 1,68 & 0 & 15 & 75 & 48 \\
\hline 13 & 0 & 0 & $-1,68$ & 15 & 37,5 & 7,68 \\
\hline 14 & 0 & 0 & 1,68 & 15 & 37,5 & 88,32 \\
\hline 15 & 0 & 0 & 0 & 15 & 37,5 & 48 \\
\hline 16 & 0 & 0 & 0 & 15 & 37,5 & 48 \\
\hline 17 & 0 & 0 & 0 & 15 & 37,5 & 48 \\
\hline 18 & 0 & 0 & 0 & 15 & 37,5 & 48 \\
\hline 19 & 0 & 0 & 0 & 15 & 37,5 & 48 \\
\hline 17 & 0 & 0 & 0 & 15 & 37,5 & 48 \\
\hline 18 & 0 & 0 & 0 & 15 & 37,5 & 48 \\
\hline 19 & 0 & 0 & 0 & 15 & 37,5 & 48 \\
\hline
\end{tabular}




\section{Artigo Geral 29}

\section{CONDUÇÃO DO ENSAIO}

O ensaio foi conduzido em três etapas:

\section{Preparação do Inóculo}

A fécula de mandioca foi pesada $(500 \mathrm{~g})$ colocada em bandejas de plástico com $5 \mathrm{~L}$ de capacidade, devidamente identificadas, suspensas com água em excesso (2 litros), para formar uma camada sobrenadante sobre o amido e colocada na estufa fechada. O equipamento foi mantido desligado e os inóculos à temperatura ambiente, somente colocados na estufa para evitar que poeira e sujidades contaminassem as amostras. O tempo de fermentação da fécula para preparação do inóculo foi de 10 dias, conforme estabelecido no protocolo experimental.

\section{Fermentação da fécula}

A fécula de mandioca foi submetida à fermentação natural em laboratório. Inicialmente, a massa de inóculo foi pesada na bandeja de plástico, com capacidade de $5 \mathrm{~L}$, e devidamente identificada. Em seguida, foram adicionados dois litros de água destilada à bandeja. Logo em seguida, $\mathrm{o}$ ácido lático foi adicionado diretamente sobre a mistura de inóculo e água conforme Tabela 2. Posteriormente, as amostras de fécula de mandioca $(500 \mathrm{~g})$ foram adicionadas às bandejas de plástico e homogeneizadas com auxilio de uma colher de inox. Finalmente, a bandeja de plástico com a massa foi levada à estufa para fermentar, a qual permaneceu desligada e os experimentos mantidos à temperatura ambiente, entre $25-28^{\circ} \mathrm{C}$.

\section{Oxidação solar}

Após o período de fermentação, o excesso de água do processo fermentativo foi drenado, por meio do transbordamento dessa, e as féculas fermentadas ,acondicionadas em bandejas revestidas com folha de alumínio, com altura de camada de massa de no máximo 0,5 $\mathrm{cm}$. Os experimentos foram submetidos à secagem solar, sendo que o tempo de exposição variou de 8 - 10 horas. Foi utilizado como parâmetro de final de secagem o mesmo utilizado pelos produtores de polvilho, que é o de pressionar a massa na mão e perceber a não formação de aglomerado para interrupção da secagem. Após este período, os polvilhos produzidos (Figura 1) foram acondicionados em sacos plásticos de polietileno de baixa densidade, devidamente identificados, mantidos à temperatura ambiente, para posteriormente serem analisados.

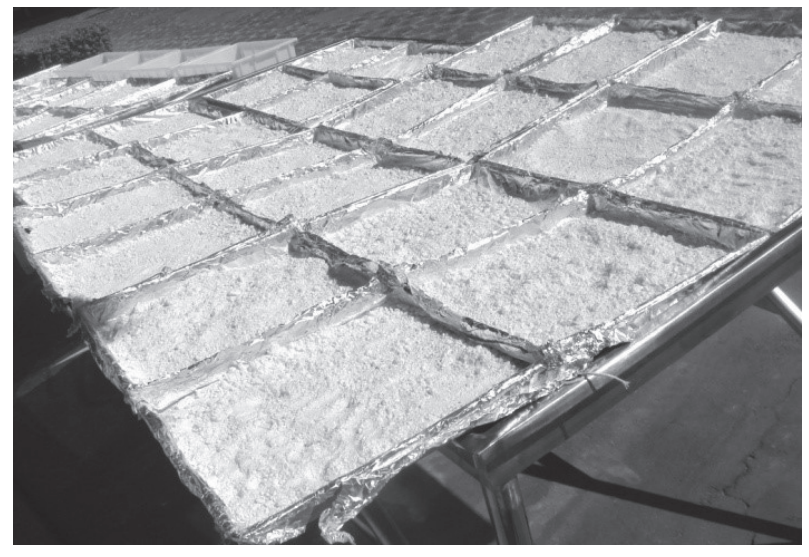

Figura 1. Polvilho seco.

\section{MÉTODOS}

\section{Físico-químicos}

A umidade e a determinação das cinzas foram determinados pelo método da $\mathrm{AACC}^{17}$.

Para a análise de proteína bruta, determinou-se o nitrogênio total pelo método oficial $\mathrm{n}^{\circ} 960.52$ da AOAC International ${ }^{18}$. O nitrogênio total foi convertido em proteína bruta, utilizando-se o fator 5,95. Os equipamentos utilizados foram o bloco digestor (Tecnal, TE-0070) e o destilador de nitrogênio (Tecnal, TE-0363).

O teor de lipídeo foi determinado em extrator de óleos e graxas (Marconi, MA 044/8/50), utilizando o método oficial $n^{\circ}$ 032/IV do Instituto Adolfo Lutz ${ }^{13}$.

Os carboidratos foram calculados por diferença.

$\mathrm{O} \mathrm{pH}$ e a acidez titulável foram determinadas segundo o método descrito por Plata Oviedo ${ }^{19}$.

A acidez foi realizada no mesmo material usado para determinação do $\mathrm{pH}$, conforme descrito por Plata Oviedo19. Após a determinação do $\mathrm{pH}$, foram adicionadas duas a quatro gotas de fenolftaleína. A mistura foi novamente agitada enquanto $\mathrm{NaOH} 0,1 \mathrm{~N}$ era adicionado, até que o $\mathrm{pH}$ atingisse 8,3. A acidez titulável foi expressa em miliequivalentes de $\mathrm{NaOH}$ por $100 \mathrm{~g}$ de amostra.

Todas as análises foram realizadas em triplicata.

\section{Microbiológicas}

Para a contagem de fungos e bolores e contagem total de mesófilos, o plaqueamento foi realizado em triplicata 
e até a diluição 10-3 utilizando metodologia do APHA $^{16}$.

Microscopia sujidades - Pesquisa de insetos, larvas e fragmentos de insetos e de pelos de roedores

Foi utilizado o método descrito pela $\mathrm{AOAC}^{18}$.

\section{Determinação da propriedade de expansão}

Para avaliar a qualidade de aplicação industrial do polvilho azedo, foram aplicados os seguintes testes de expansão de biscoitos, segundo metodologia proposta por Maeda e $\mathrm{Cereda}^{20}$. Na preparação dos biscoitos, foram pesados $50 \mathrm{~g}$ de polvilho azedo e colocados, aproximadamente, $40 \mathrm{~mL}$ de água fervente sobre a amostra. A massa foi modelada, testando-se a consistência nas mãos até tornar-se suficientemente homogênea e macia para ser moldada. Caso permanecesse dura e quebradiça, um pouco mais de água fervente seria adicionada até obter-se a consistência ideal. Com a massa modelada, foram confeccionados três biscoitos redondos de $10 \mathrm{~g}$ cada, aproximadamente, os quais foram distribuídos em assadeira e levados ao forno elétrico termoestatizado a temperatura de $200{ }^{\circ} \mathrm{C}$, por 25 minutos. Após esfriarem, os biscoitos confeccionados foram medidos com o uso do paquímetro digital, SHAN ${ }^{\circledR}$ através da medida do diâmetro médio, antes e após o forneamento. O índice de expansão foi calculado, segundo Pereira et al. ${ }^{15}$ e Marcon ${ }^{3}$, por meio da razão entre o diâmetro médio final (após assado) e o diâmetro médio inicial (antes de assado).

\section{Propriedades viscoamilográficas}

As propriedades da pasta dos polvilhos foram avaliadas pelo Rapid Visco Analyser (RVA), série 4, da Newport Scientific e programa de computador Thermocline for Windows, da Empresa Brasileira de Pesquisa Agropecuária-EMBRAPA, em Goiânia. Foi utilizada a concentração de 2,5 g de amostra em $25 \mathrm{~mL}$ de água, corrigidos para a base de $14 \%$ de umidade. O equipamento operou no modo standard 2 (NEWPORT SCIENTIFIC, 1995), com modificações na programação: $50^{\circ} \mathrm{C}$ por 1 minuto, aquecimento de 50 a $92{ }^{\circ} \mathrm{C}$ a uma taxa de $5,6{ }^{\circ} \mathrm{C} / \mathrm{min}$., manutenção da pasta a $92{ }^{\circ} \mathrm{C}$ por 5 minutos, resfriamento de 92 a $50{ }^{\circ} \mathrm{C}$ à uma taxa de $5,6^{\circ} \mathrm{C}$ / min e 01 mim para finalização.

Dos perfis viscoamilográficos obtidos, foram extraídos os parâmetros: temperatura de pasta, viscosidade máxima (pico), quebra de viscosidade (diferença entre a viscosidade máxima e da pasta mantida a $92{ }^{\circ} \mathrm{C}$ por 5 minutos), viscosidade final e tendência à retrogradação (diferença entre viscosidade final e da pasta a $92{ }^{\circ} \mathrm{C}$ por 5 minutos). A viscosidade foi expressa em RVU (Rapid Visco Units).

\section{Microscopia eletrônica de varredura}

A microscopia eletrônica não foi realizada em todas as amostras, haja vista o número de experimentos. Para essa análise selecionou-se a fécula, o polvilho de maior expansão e o polvilho artesanal, para fins de comparação. As amostras foram diluídas em álcool etílico $100 \%$ $(1 / 10 \mathrm{p} / \mathrm{v})$ e posteriormente duas gotas da solução foram colocadas sobre os "stubs". Após este procedimento, as amostras foram cobertas em $10 \mu \mathrm{m}$ de ouro metalizador (MED-010 da Balzers) e avaliadas em microscópio eletrônico de varredura (SEM 515 Philips), sob tensão de $20 \mathrm{KV}$ e tamanhos de 120, 200, 2000 e 4000 vezes. Foram escolhidas as microscopias com tamanho de 2000 vezes para serem apresentadas neste trabalho.

\subsection{MÉTODOS ESTATÍSTICO}

A análise estatística foi realizada no programa SAS for windows e passos do Statistica for windows versão 7.0 (PROC ANOVA / TUKEY, PROC RSREG; ANOVA / MANOVA) ${ }^{21}$.

Para avaliação dos resultados de expansão do polvilho, foi empregada a análise de variância (ANOVA) e determinada a significância pelo emprego do teste $\mathrm{F}$ ( $\mathrm{P}$ $\leq 0,05)$. Para o estudo comparativo das médias, foi feito teste Tukey, verificando-se as médias estatisticamente significativas ao nível de 5\% de probabilidade $^{22 ;}{ }^{23}$. A Metodologia de Superfície de Resposta (MSR) foi empregada para a análise do efeito combinado das variáveis independentes $(\mathrm{x} 1, \mathrm{x} 2, \mathrm{x} 3)$ nas respostas avaliadas (y1). A resposta pode ser escrita como sendo função (f) de $x$ : $y 1=f(x 1, x 2, x 3)$.

As médias dos dados de cada um dos 19 experimentos para cada resposta foram tratadas por análise de regressão múltipla da MSR, para desenvolver modelos matemáticos de segunda ordem, contendo termos lineares, quadráticos e de interação das 3 variáveis independentes, com o emprego do SAS for windows (23). A equação geral deste modelo preditivo é representada pela Equação 1. 


$$
y_{i}=\beta_{0}+\beta_{1} x_{1}+\beta_{2} x_{2}+\beta_{3} x_{3}+\beta_{11} x_{1}^{2}+\beta_{22} x_{2}^{2}+\beta_{33} x_{3}^{2}+\beta_{12} x_{1} x_{2}+\beta_{13} x_{1} x_{3}+\beta_{23} x_{2} x_{3}+€
$$

Em que $\mathrm{y}_{1}$ é igual a função resposta genérica ou variável dependente; $\mathrm{x}_{1}, \mathrm{x}_{2}, \mathrm{x}_{3}$ é igual ao níveis codificados das variáveis independentes; $\beta_{0}$ é igual ao ponto central do sistema ou ponto estacionário; $\beta$ s é igual ao coeficientes estimados pelo método dos mínimos quadrados; $€$ é igual ao resíduo que mede o erro experimental, apresentando uma distribuição normal com média zero e variância igual a $2 \mathrm{~s}$

\section{Resultados e Discussão}

\section{DIAGNÓSTICO DA QUALIDADE DO POLVILHO PRODUZIDO MUNICÍPIOS DO ESTADO DE GOIÁS}

O diagnóstico foi realizado em produtores dos municípios com maior produção de polvilho do Estado de Goiás, sendo estes: Bela Vista de Goiás, Piracanjuba, Porangatu e Inhumas. Foram visitados oito produtores e observado o processo de produção do polvilho. A realidade encontrada foi de uma produção marcada pelo empirismo e falta de padronização nas etapas de fermentação e secagem, além de péssimas condições higiênico-sanitárias de processamento.

As amostras recolhidas foram analisadas quanto ao índice de expansão (IE), pH, acidez, teor de amido, umidade, resíduo mineral, presença de bolores e leveduras, bactérias mesófilas e microscopia (presença de sujidades).

Para o IE, 63\% das amostras apresentaram variação entre $0,5-1,0 ; 12,5 \%$ entre $1,0-1,5$ e $25 \%$ entre $1,5-$ 2,0. A maioria, portanto, apresentaram baixas expansões.

Em relação ao pH, observou-se que $62,5 \%$ das amostras apresentaram variação no $\mathrm{pH}$ no intervalo de $3-4,24,5 \%$ entre $4-5$ e $13 \%$ entre $5-6$. Não existe especificação na legislação a respeito do $\mathrm{pH}$ de polvilho azedo. A faixa de variação de $\mathrm{pH}$, obtida por Marcon (24), ao analisar amostras de polvilho azedo, foi entre 3,73 - 4,76. Portanto, semelhante à observada neste trabalho.

Sabendo que a acidez máxima permitida pela legislação brasileira é de 5,0 mL NaOH $1 \mathrm{~N} / 100 \mathrm{~g}$ (25), observa-se que somente $12,5 \%$ das amostras não atenderam ao padrão especificado, entre $6-7 \mathrm{~mL} \mathrm{NaOH}$ $1 \mathrm{~N} / 100 \mathrm{~g}$. Enquanto que $62,5 \%$ obtiveram acidez entre 2-3 mL NaOH $1 \mathrm{~N} / 100 \mathrm{~g} ; 12,5 \%$ entre $3-4 \mathrm{~mL} \mathrm{NaOH}$ $1 \mathrm{~N} / 100 \mathrm{~g}$ e $12,5 \%$ entre $4-5 \mathrm{~mL} \mathrm{NaOH} 1 \mathrm{~N} / 100 \mathrm{~g}$.

A legislação prevê um teor de amido de, no mínimo, $80,0 \mathrm{~g}$ (100 g)-1 (25). Nas amostras avaliadas, observouse que todas atenderam à legislação, com $37,5 \%$ com teor de amido de $86 \mathrm{~g}$ (100 g)-1; 37,5\% com $87 \mathrm{~g}$ (100 g)-1 e $25 \%$ com $88 \mathrm{~g}(100 \mathrm{~g})-1$.

O teor de umidade variou de 7,00 a $9,00 \mathrm{em} 12,5 \%$ das amostras, 9,00 a $11,00 \mathrm{~g}(100 \mathrm{~g})-1 \mathrm{em} 50 \%$ das amostras e 11,00 a $13,00 \mathrm{~g} \mathrm{(100} \mathrm{g)-1} \mathrm{em} \mathrm{37,5 \% .} \mathrm{Considerando} \mathrm{que}$ o padrão previsto na legislação é de no máximo 18 g (100 g)-1 (26) pode-se afirmar que as amostras atenderam à legislação brasileira.

Com relação ao teor de cinzas, todas as amostras atenderam aos parâmetros exigidos na legislação de, no máximo, $0,5 \mathrm{~g}$ (100 g)-1, sendo que a maior frequência foi observada entre $0,05-0,08 \mathrm{~g}(100 \mathrm{~g})-1$, com $50 \%$ das amostras neste intervalo e os maiores valores encontrados foram de 0,11 a $0,14 \mathrm{~g}(100 \mathrm{~g})-1$ em $13 \%$ das amostras.

Com relação à análise microbiológica, 100\% das amostras apresentaram contagem para bolores e leveduras menor ou igual a $40 \mathrm{UFC}$. g-1, portanto todas atendem à legislação, que prevê contagem de até 103 UFC . g-1 (25). Em relação à contagem de bactérias mesófilas, $62,5 \%$ das amostras apresentaram contagem dentro da faixa de $10-102$ UFC . g- 1 e 37,5\% das amostras dentro da faixa de $102-103$ UFC . g-1. Considerando o padrão previsto na legislação de 5x105 UFC . g-1 (25), pode-se afirmar que todas as amostras apresentaram valores dentro da faixa estabelecida.

Para a análise de microscopia, 100\% das amostras apresentaram contaminações, sendo $75 \%$ com presença de cascas e $25 \%$ com presença de casca e insetos, o alto grau de contaminação provavelmente é devido à falta de condições higiênico-sanitárias ao longo do processo.

Observou-se também que, apesar dos problemas de falta de uniformidade, a qualidade microbiana das amostras se enquadrou nos limites estabelecidos pela legislação brasileira. As possíveis razões para tal fato são a alta acidez do produto e o efeito da radiação ultravioleta do sol. 
Apesar das precárias condições de alguns estabelecimentos produtores de polvilho, apenas 12,5\% das amostras não se encontravam dentro dos padrões estabelecidos pela legislação, referente à acidez das amostras. Portanto, conclui-se que, com pequenas interferências no processo produtivo, pode-se adequar a totalidade do polvilho aos padrões de comercialização, principalmente, com a implantação de boas práticas de fabricação e controles no processamento.

\section{CARACTERIZAÇÃO DA FÉCULA DE MANDIOCA}

As características físico-químicas e contagem total de mesófilos da amostra de fécula de mandioca in natura utilizada nos ensaios são apresentadas na Tabela 3.

Tabela 3. Características físico-químicas da fécula de mandioca utilizada no ensaio científico

\begin{tabular}{|l|l|}
\hline Características & Média \pm Desvio Padrão \\
\hline Índice de expansão & $1,24 \pm 0,02$ \\
\hline $\mathrm{pH}$ & $5,48 \pm 0,37$ \\
\hline $\begin{array}{l}\text { Acidez titulável }[\mathrm{mL} \text { de } \\
\left.\text { NAOH } 1 \mathrm{~N}(100 \mathrm{~g})^{-1}\right]\end{array}$ & $1,60 \pm 0,05$ \\
\hline Amido $\left[\mathrm{g}(100 \mathrm{~g})^{-1}\right]$ & $98,45 \pm 0,00$ \\
\hline Amilose $\left[\mathrm{g}(100 \mathrm{~g})^{-1}\right]$ & $14,92 \pm 0,01$ \\
\hline Amilopectina $\left[\mathrm{g}(100 \mathrm{~g})^{-1}\right]$ & $83,53 \pm 0,01$ \\
\hline Umidade $\left[\mathrm{g}(100 \mathrm{~g})^{-1}\right]$ & $11,95 \pm 0,07$ \\
\hline Cinzas $\left[\mathrm{g}(100 \mathrm{~g})^{-1}\right]$ & $0,05 \pm 0,01$ \\
\hline Proteína $\left[\mathrm{g}(100 \mathrm{~g})^{-1}\right]$ & $0,10 \pm 0,07$ \\
\hline Lipídeos [g $\left.(100 \mathrm{~g})^{-1}\right]$ & $0,20 \pm 0,01$ \\
\hline Absorção de água $\left(\mathrm{mL} 50 \mathrm{~g}^{-1}\right)$ & $39,00 \pm 0,52$ \\
\hline $\begin{array}{l}\text { Contagem total de mesófilos } \\
\left(\text { UFC } \mathrm{g}^{-1}\right)\end{array}$ & 101 \\
\hline
\end{tabular}

O índice de expansão da fécula de mandioca utilizada foi de 1,24 , portanto está dentro da faixa de variação encontrada por Marcon (24), de 1,18 -1,49, ao analisar cinco amostras de fécula de mandioca comerciais, dentre elas a marca $Y O K I \circledR$.
$\mathrm{O}$ valor de $\mathrm{pH}$ encontrado foi de 5,48, portanto abaixo do valor apontado como normal para fécula de mandioca, que é de 6,2. Valor 3\% maior foi determinado por Cavallet et al. (27), na avaliação da fécula de mandioca, encontrando $\mathrm{pH}$ de 5,6. Esta diferença é provavelmente devido a variações de clima, solo, e cultivares utilizadas.

A acidez titulável apresentou-se acima de $0,94 \mathrm{~mL}$ de NAOH $1 \mathrm{~N}$ (100g)-1, valor esse tido como comum para fécula de mandioca. Cavallet et al. (27) encontrou maior valor, 1,54 mL de NAOH $1 \mathrm{~N}$ (100 g)-1, quando analisou a fécula de mandioca da cultivar Branca de Santa Catarina, da cidade de Marechal Cândido Rondon (PR). Observa-se que o teor de amido da fécula de mandioca utilizada, encontra-se dentro dos padrões da legislação sendo superior a $80,00 \mathrm{~g}$ (100 g)-1, e próximos aos encontrados por Plata Oviedo e Camargo (28) de 99,60 g (100 g)-1 e superior ao encontrado por Cavallet (29) 96,94 g (100 g)-1.

O valor de amilose detectado [14,92 g (100 g)-1] foi inferior ao encontrado por Takizawa et al. (30) de 18,6 g (100 g)-1 e 8,5\% menor que o encontrado por Leonel et al. (31) de 16,3 g (100 g)-1 ao analisar fécula de mandioca da variedade Branca de Santa Catarina.

A umidade de 11,95 g (100 g)-1 está de acordo com a legislação que prevê para a fécula de mandioca: umidade máxima 18,0 g (100 g)-1 (26) e dentro da faixa que Marcon (24) encontrou para as féculas analisadas 11,72$14,19 \mathrm{~g}$ (100g)-1. Valor 8\% maior foi encontrado por Garcia e Leonel (10) para a fécula de mandioca 12,95 g (100 g)-1.

O teor de cinzas de $0,05 \mathrm{~g}$ (100 g)-1 está de acordo com a legislação que prevê no máximo $0,05 \mathrm{~g}(100 \mathrm{~g})-1$ de cinza (25).

Observa-se que o valor de lipídeos encontrado para a fécula de mandioca de 0,2 g (100g)-1 é $10 \%$ menor que o encontrado por Cereda et al.(32), enquanto Sarmento (33) quantificou 0,22 g (100 g)-1.

Para valor de proteína foi obtido teor de $0,1 \mathrm{~g}(100 \mathrm{~g})-1$ que coincide com o encontrado por Cereda (8) na sua avaliação da fécula de mandioca.

Quanto a contagem total de mesófilos, o valor encontrado, 101 UFC g-1, indica baixo índice de contaminação microbiana.

A fécula de mandioca nativa utilizada nesse ensaio atendeu aos parâmetros exigidos pela legislação brasileira. 


\section{ÍNDICE DE EXPANSÃO DOS POLVILHOS EXPERIMENTAIS}

Os dados obtidos para IE, no segundo ensaio, com as novas faixas de variação de volume de ácido lático, massa de inóculo e a mesma variação do tempo de fermentação estão apresentados na Tabela 4.

Tabela 4. Médias e desvios-padrão do índice de expansão dos polvilhos experimentais em função do volume de ácido lático (X1), massa de inóculo (X2) e tempo de fermentação (X3).

\begin{tabular}{|c|c|c|c|c|}
\hline \multirow[b]{2}{*}{ Experimento } & \multicolumn{3}{|c|}{ Variáveis independentes } & \multirow{2}{*}{$\begin{array}{l}\text { Resposta } \\
\text { Índice de } \\
\text { expansão }\end{array}$} \\
\hline & $\begin{array}{l}\text { Volume de } \\
\text { ácido lático } \\
\text { adicionado } \\
(\mathrm{mL})\end{array}$ & $\begin{array}{l}\text { Massa de } \\
\text { inóculo } \\
(\mathrm{g})\end{array}$ & $\begin{array}{l}\text { Tempo de } \\
\text { fermentação } \\
\text { (h) }\end{array}$ & \\
\hline 1 & 6,0 & 15,2 & 24,00 & $1,7 \pm 0,07$ \\
\hline 2 & 24,0 & 15,2 & 24,00 & $1,8 \pm 0,10$ \\
\hline 3 & 6,0 & 59,8 & 24,00 & $1,6 \pm 0,11$ \\
\hline 4 & 24,0 & 59,8 & 24,00 & $1,7 \pm 0,14$ \\
\hline 5 & 6,0 & 15,2 & 72,00 & $1,6 \pm 0,07$ \\
\hline 6 & 24,0 & 15,2 & 72,00 & $1,9 \pm 0,10$ \\
\hline 7 & 6,0 & 59,8 & 72,00 & $1,7 \pm 0,08$ \\
\hline 8 & 24,0 & 59,8 & 72,00 & $1,8 \pm 0,08$ \\
\hline 9 & 0,0 & 37,5 & 48,00 & $1,6 \pm 0,09$ \\
\hline 10 & 30,0 & 37,5 & 48,00 & $1,6 \pm 0,14$ \\
\hline 11 & 15,0 & 0,0 & 48,00 & $1,8 \pm 0,10$ \\
\hline 12 & 15,0 & 75,0 & 48,00 & $1,7 \pm 0,12$ \\
\hline 13 & 15,0 & 37,5 & 7,68 & $1,7 \pm 0,08$ \\
\hline 14 & 15,0 & 37,5 & 88,32 & $1,6 \pm 0,06$ \\
\hline 15 & 15,0 & 37,5 & 48,00 & $1,9 \pm 0,08$ \\
\hline 16 & 15,0 & 37,5 & 48,00 & $2,0 \pm 0,06$ \\
\hline 17 & 15,0 & 37,5 & 48,00 & $2,1 \pm 0,10$ \\
\hline 18 & 15,0 & 37,5 & 48,00 & $2,0 \pm 0,19$ \\
\hline 19 & 15,0 & 37,5 & 48,00 & $1,9 \pm 0,09$ \\
\hline
\end{tabular}

A análise de variância para o IE mostrou que o modelo matemático completo foi significativo $(\mathrm{P}=0,0188)$, com coeficiente de determinação de $81,51 \%$, falta de ajuste não significativa $(\mathrm{FA}=0,3605)$, coeficiente de variação baixo (5,35\%), podendo ser considerado preditivo. Os efeitos quadráticos do volume de ácido lático $(\mathrm{P}=$ 0,000065), da massa de inóculo ( $\mathrm{P}=0,009525)$ e do tempo de fermentação $(\mathrm{P}=0,000452)$, foram significativos. $\mathrm{O}$ efeito linear do volume de ácido lático, apesar de não ser significativo $(\mathrm{P}=0,083)$, foi mantido para melhorar o ajuste do modelo. O modelo ajustado e o coeficiente de determinação (R2) estão apresentados na Tabela 3.

A partir deste modelo, foram traçados gráficos que apresenta a variação do IE em função da massa de inóculo (g) e do tempo de fermentação (h), com o volume de ácido lático fixado em $6 \mathrm{~mL}, 15 \mathrm{~mL}$ e $24 \mathrm{~mL}$ (Figura 2 a,b,c).
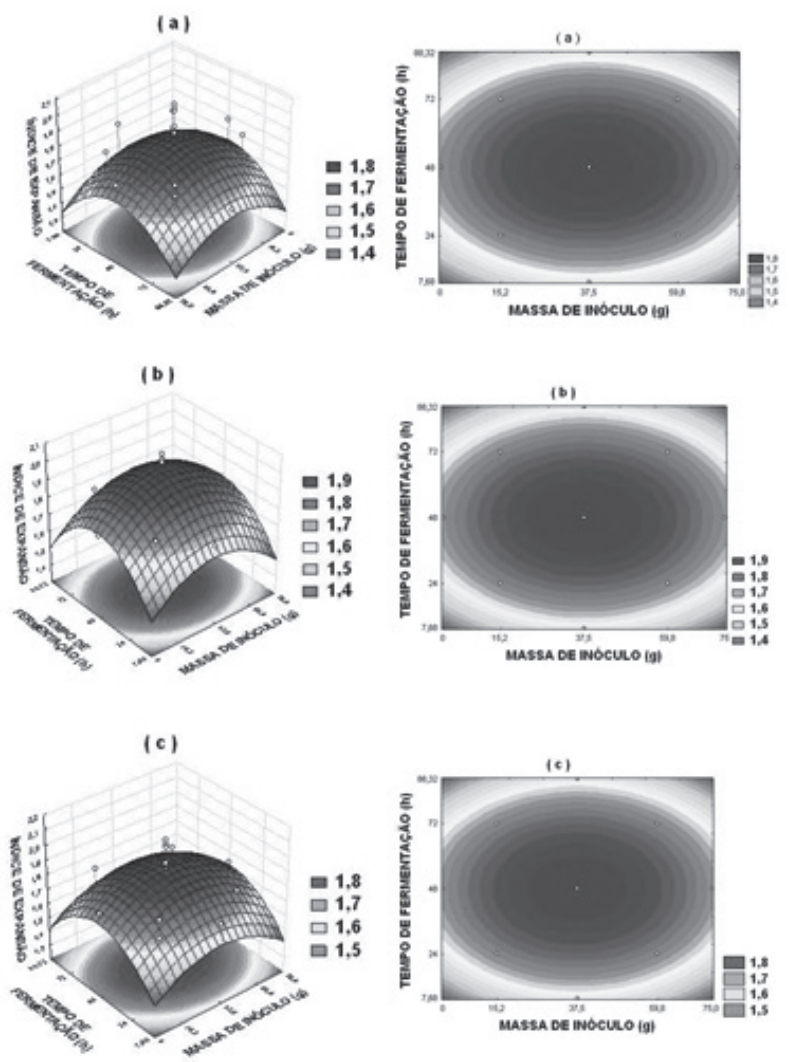

Figura 2. Índice de expansão dos polvilhos de mandioca experimentais em função do tempo de fermentação (h) e da massa de inóculo (g), com o volume de ácido lático fixado em $6 \mathrm{~mL}(\mathrm{a}), 15 \mathrm{~mL}(\mathrm{~b})$ e $24 \mathrm{~mL}(\mathrm{c})$.

Ao analisar a Figura 2a, observa-se que quando o volume de ácido lático é igual a $6 \mathrm{~mL}$, a região de máximo índice de expansão $(1,8)$ está compreendida no intervalo 27,3 - 48,5 g para massa de inóculo e de 38,8 - 54,8 h para o tempo de fermentação. Já quando o volume de ácido lático é de $15 \mathrm{~mL}$, Figura $2 \mathrm{~b}$, a região de 
máxima expansão $(1,9)$ é observada quando o intervalo de variação para massa de inóculo é de 29,8 - 45,3 g e de 41,8 - 50,8 h para o tempo de fermentação. Na Figura 2 c, a região de máxima expansão $(1,8)$ ocorre quando o intervalo de variação para massa de inóculo é de 23,0 $51,2 \mathrm{~g}$ e para o tempo de fermentação de 40,8 - 57,6 h.

Observa-se, claramente, nos gráficos da Figura 2, o efeito quadrático do tempo de fermentação e massa de inóculo. $\mathrm{O}$ índice de expansão aumentou com a elevação destas variáveis independentes até atingir a região de máximo, diminuindo em seguida.

Para melhor visualização do efeito do volume de ácido lático, também foram elaborados gráficos com a variação do Índice de expansão em função do volume de ácido lático $(\mathrm{mL})$ e do tempo de fermentação (h), fixando-se a massa de inóculo em 15,2 g (a), 37,5 g (b) e $59,8 \mathrm{~g}$ (c) (Figura 3).

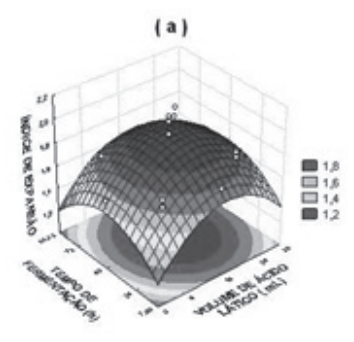

(b)

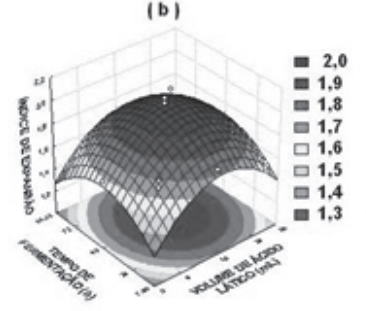

$|c|$
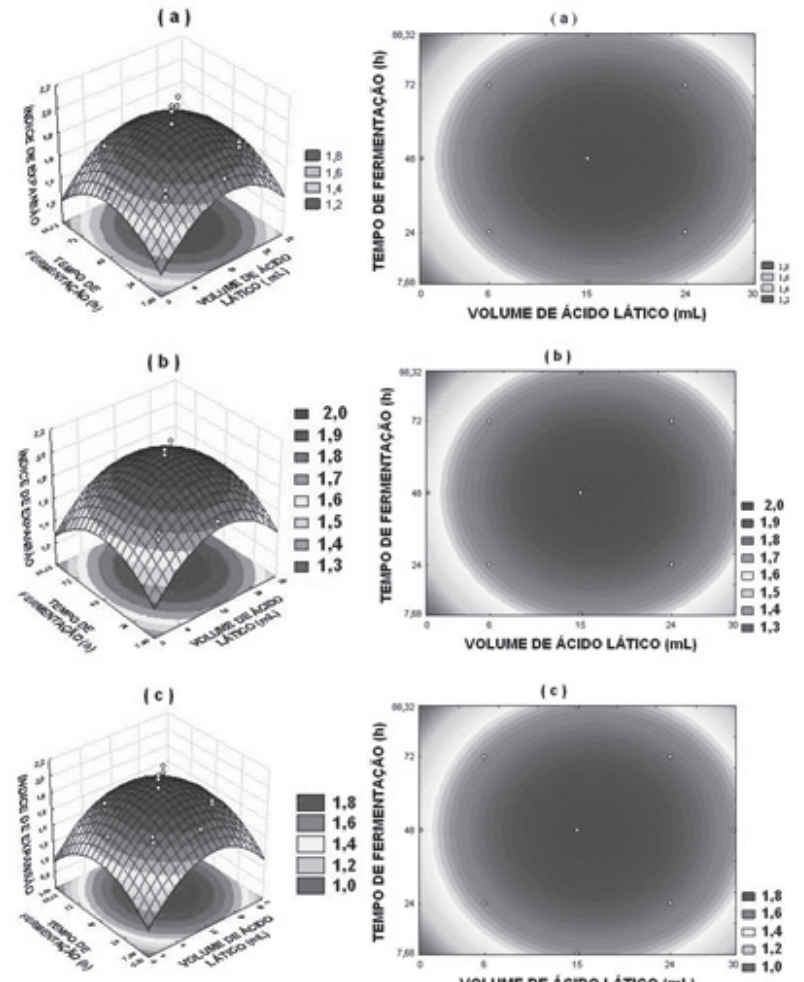

(c)

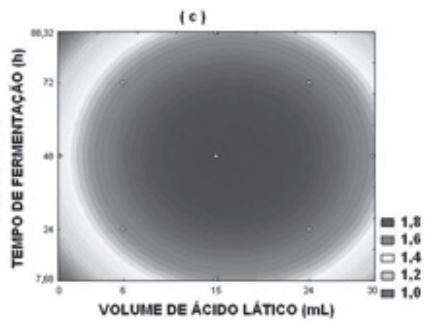

Figura 3. Índice de expansão dos polvilhos de mandioca experimentais em função do tempo de fermentação (h) e do volume de ácido lático (mL), com massa de inóculo fixada em 15,2 g (a), 37,5 g (b) e 59,8 g (c).
Ao analisar a Figura 3a, observa-se que, quando a massa de inóculo é igual a $15,2 \mathrm{~g}$, a região de máxima expansão $(1,8)$ localiza-se no intervalo fixado em 10,12 22,15 mL para o volume de ácido lático e de 36,0 - 62,4 h para o tempo de fermentação.

Quando a massa de inóculo foi fixada em 37,5 g, Figura 3 b, a região de máxima expansão $(2,0)$ é compreendida quando o intervalo de variação para o volume de ácido lático é de 10,8 - 21,3 mL e de 36,0 - 65,3 h para o tempo de fermentação.

$\mathrm{Na}$ Figura 3c, a região de máxima expansão $(1,8)$ ocorreu quando o intervalo de variação para volume de ácido lático foi de 10,8 - 21,8 mL para o volume de ácido lático e de 36,0 - 62,4 h para o tempo de fermentação

Das condições citadas, a segunda combinação ternária é a ideal, pois propiciou o maior índice de expansão e o menor tempo de fermentação. Considerando as dificuldades operacionais que as indústrias enfrentam para atender o tempo de fermentação necessário à produção do polvilho, entendemos que, devido à diminuição dos custos operacionais e consequente aumento do fluxo de produção ,o menor tempo de fermentação é a melhor opção.

Ainda considerando a combinação ternária como ideal, temos que o volume mínimo de ácido lático a ser adicionada é de 10,8 mL (500 g)-1 de fécula, ou seja, $2 \%$ que quando extrapolados para uma produção de 1 tonelada diária teríamos um consumo de $20 \mathrm{~L}$ de ácido lático, e um incremento de R \$240,00 ao custo de produção. Porém, os custos oriundos da acidificação são pequenos quando comprados ao ganho propiciado pela redução do tempo de fermentação 48 - 60 d para 48 h. Garcia e Leonel (2005) concluíram que a concentração de ácido lático, durante o processo de modificação fotoquímica, interfere no índice de expansão, sendo o aumento da expansão significativo com o aumento da concentração de ácido lático.

Em relação à adição da massa de inóculo, não haveria um incremento de custo, uma vez que essa retorna ao processo e também pouco impacto na produção, tendo em vista que a massa de inóculo adicionada por tonelada seria de $75 \mathrm{~kg}$, podendo ser preparado em pequenos tanques, já utilizados no processo produtivo do polvilho.

Existem divergências quanto à forma de avaliação da expansão do polvilho azedo. Alguns autores referem-se à densidade, outros, a volume específico e outros, à índice de expansão, resultando em dados conflitantes quanto aos 
parâmetros de expansão considerados ideais (ASCHERI e VILELA, 1995; PEREIRA et al., 1999; MAEDA e CEREDA, 2001; PLATA OVIEDO e CAMARGO, 2005).

Demiate et al. (2000) e Silva et al. (2006) afirmaram que o método de avaliação da propriedade de expansão, utilizando o painço para medir o volume de deslocamento, não é muito sensível e possui baixa reprodutibilidade. Demiate et al. (2000) concluíram que o índice de expansão apresentou-se como uma das características mais adequadas para a caracterização do polvilho azedo utilizado em biscoitos de polvilho, uma vez que há relação entre a expansão e o peso do produto, existindo uma relação com o grau de qualidade.

Na Figura 4, observa-se a aparência e tamanho final do biscoito produzido com o polvilho do experimento 18 , ponto que se encontra na região de máxima expansão segundo os gráficos analisados, além do polvilho artesanal de maior expansão verificada no diagnóstico e a fécula de mandioca utilizada para produção do polvilho no ensaio. Pode-se observar uma visível diferença entre os produtos do experimento 18 foram maiores que os produzidos com polvilho artesanal e a fécula de mandioca.

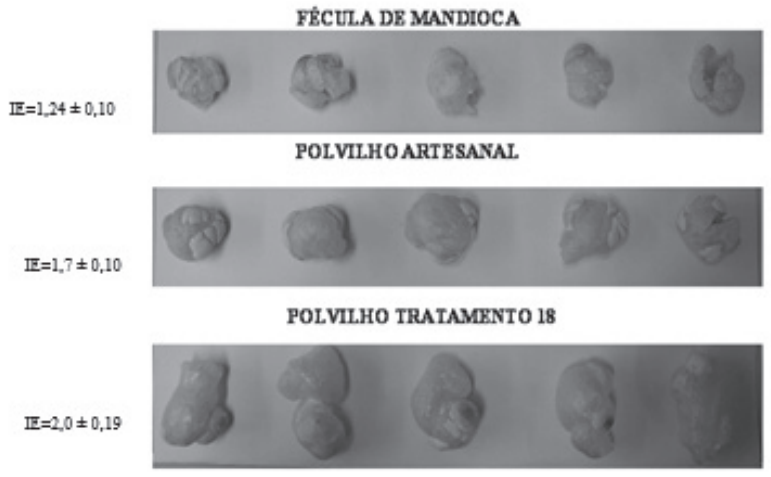

Figura 4. Índices de expansão da fécula de mandioca, do polvilho artesanal e polvilho do experimento 18 .

A maior expansão alcançada $(\mathrm{IE}=2,0)$ foi do polvilho com $48 \mathrm{~h}$ de fermentação. Esse valor se aproxima do resultado alcançado por Marcon (24) para a amostra de maior expansão (PAM). A autora, ao analisar polvilhos azedos com fermentação de 48 dias, polvilho azedo seco em estufa (PASE), polvilho azedo seco ao sol (PASSOL) e polvilho azedo referência - mix (PAM), obteve índices de expansão com valores de 1,46, 1,66 e 2,00, respectivamente. A autora concluiu que o IE aumentou proporcionalmente em relação ao volume específico para as diferentes amostras analisadas e foi inversamente proporcional à densidade específica. A amostra PAM, que corresponde a um pool das amostras preferidas pelos padeiros, referência como polvilho azedo de boa performance, apresentou o melhor índice de expansão $(2,0)$, o maior volume específico $(10,07 \mathrm{~mL}$ g-1) e a menor densidade específica $(0,1 \mathrm{~mL}$ g- 1$)$.

Pereira et al. (15) avaliaram féculas de araruta, batatabaroa, batata-inglesa e mandioca como fontes alternativas na produção de amidos fermentados com propriedade de expansão e compararam com o polvilho azedo industrial. Concluíram que os biscoitos obtidos a partir do polvilho azedo comercial foram os que apresentaram maior expansão $(1,99)$, valor $1 \%$ menor ao alcançado neste trabalho.

\section{ACIDEZ E PH}

Na Tabela 5, são apresentadas as médias de pH e acidez dos polvilhos, assim como as condições experimentais.

A análise de variância para a acidez titulável mostrou que o modelo matemático completo foi significativo ( $\mathrm{P}=0,0000)$, a falta de ajuste não foi significativa $(\mathrm{FA}=0.0820)$, o coeficiente de variação foi médio (11,35\%) e $97,59 \%$ das respostas são explicáveis pelo modelo completo, sendo reduzido para $97,00 \%$ no modelo ajustado, podendo ser considerado preditivo. Os efeitos linear e quadrático do volume de ácido lático foram significativos $(\mathrm{P}=0,000 ; \mathrm{P}=0,003$, respectivamente), assim como o efeito da interação entre volume de ácido lático e massa de inóculo ( $\mathrm{P}$ $=0,030)$. Os efeitos lineares da massa de inóculo ( $\mathrm{P}$ $=0,1356)$ e quadrático do tempo de fermentação $(\mathrm{P}$ $=0,2374)$ e, a interação da massa de inóculo e tempo de fermentação $(P=0,2319)$ não foram significativos, mas foram mantidos no modelo ajustado.

A partir do modelo ajustado (Tabela 6), foi traçado gráfico que apresenta a variação de acidez em função do volume de ácido lático $(\mathrm{mL})$ e da massa de inóculo $(\mathrm{g})$, como pode ser observado na Figura 5. 
Tabela 5. Modelo de regressão ajustado e coeficiente de determinação (R2) do Índice de Expansão em função do volume de ácido lático (mL), da massa de inóculo (g) e do tempo de fermentação (h).

\begin{tabular}{|c|c|c|}
\hline Resposta & MODELO & $\mathrm{R} 2$ \\
\hline $\begin{array}{l}\text { Índice de } \\
\text { Expansão }\end{array}$ & $y=1,9836+0,04121 x_{1}-0,1242 \mathrm{x}_{1}^{2}-0,0665 \mathrm{x}_{2}^{2}-0,1009 \mathrm{x}_{3}^{2}$ & 0,79 \\
\hline
\end{tabular}

y: resposta; x1: Volume de Ácido lático (mL); x2: Massa de Inóculo (g); x3: Tempo de Fermentação (h). Itálico: o efeito apesar de não ser significativo ao nível de $5 \%$ de probabilidade de erro contribuiu com a resposta.

(a)
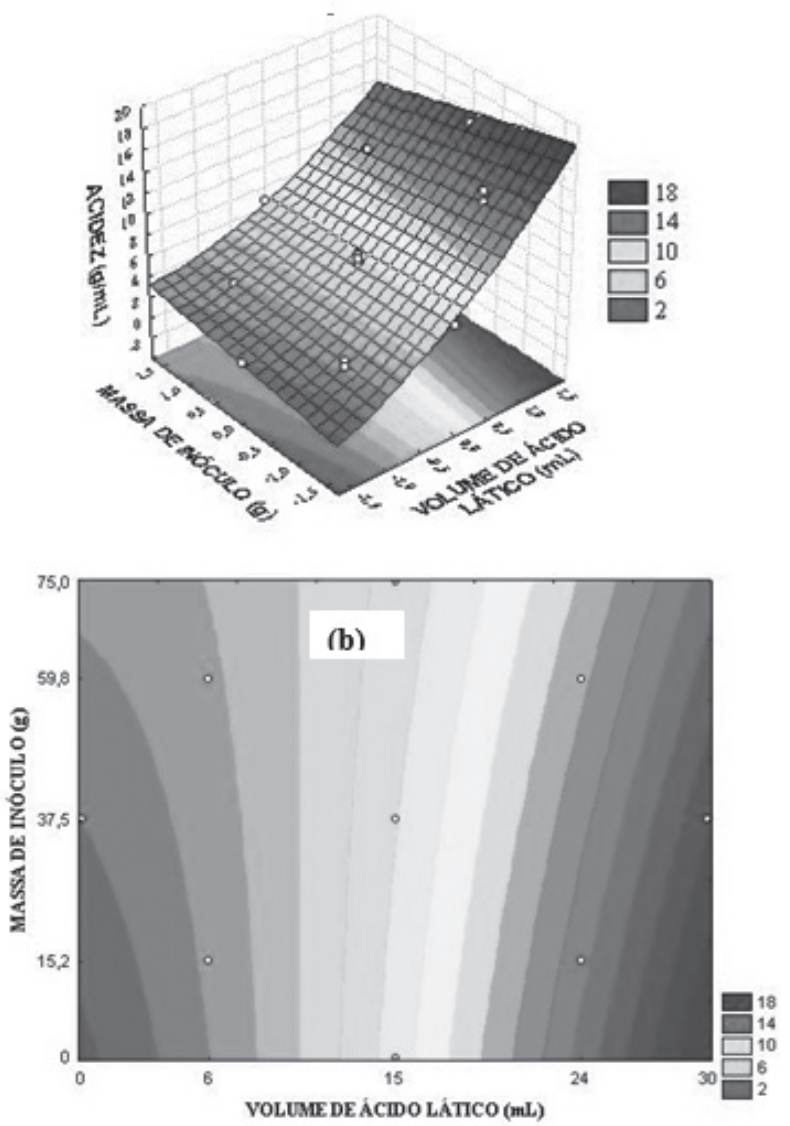

Figura 5. Acidez titulável dos polvilhos de mandioca experimentais, em função do volume de ácido lático (X1) e da massa de inóculo (X2), com o tempo de fermentação (X3) fixado em $48 \mathrm{~h}$.
Tabela 6. Médias e desvios-padrão da acidez e do $\mathrm{pH}$ dos polvilhos de mandioca experimentais obtidos em função do volume de ácido lático (X1), massa de inóculo (X2) e tempo de fermentação (X3).

\begin{tabular}{|c|c|c|c|c|c|}
\hline \multirow[b]{2}{*}{ Experimento } & \multicolumn{3}{|c|}{ Variáveis independentes } & \multicolumn{2}{|c|}{ Resposta } \\
\hline & $\begin{array}{c}\text { Volume } \\
\text { de ácido } \\
\text { lático } \\
\text { adicionado } \\
(\mathrm{mL})\end{array}$ & $\begin{array}{l}\text { Massa } \\
\text { de } \\
\text { inóculo } \\
\text { (g) }\end{array}$ & $\begin{array}{l}\text { Tempo de } \\
\text { fermentação } \\
\text { (h) }\end{array}$ & $\begin{array}{l}\text { Índice de } \\
\text { expansão }\end{array}$ & $\mathrm{pH}$ \\
\hline 1 & 6,0 & 15,2 & 24 & $\begin{array}{c}3,70 \pm \\
0,00\end{array}$ & $\begin{array}{c}3,16 \pm \\
0,00\end{array}$ \\
\hline 2 & 24,0 & 15,2 & 24 & $\begin{array}{c}13,75 \pm \\
0,35\end{array}$ & $\begin{array}{c}2,60 \pm \\
0,03\end{array}$ \\
\hline 3 & 6,0 & 59,8 & 24 & $\begin{array}{c}3,35 \pm \\
0,07\end{array}$ & $\begin{array}{c}3,06 \pm \\
0,09\end{array}$ \\
\hline 4 & 24,0 & 59,8 & 24 & $\begin{array}{c}10,40 \pm \\
0,14\end{array}$ & $\begin{array}{c}2,73 \pm \\
0,01\end{array}$ \\
\hline 5 & 6,0 & 15,2 & 72 & $\begin{array}{c}3,20 \pm \\
0,00\end{array}$ & $\begin{array}{c}3,24 \pm \\
0,01\end{array}$ \\
\hline 6 & 24,0 & 15,2 & 72 & $\begin{array}{c}12,75 \pm \\
0,21\end{array}$ & $\begin{array}{c}2,69 \pm \\
0,01\end{array}$ \\
\hline 7 & 6,0 & 59,8 & 72 & $\begin{array}{c}3,75 \pm \\
0,07\end{array}$ & $\begin{array}{c}3,09 \pm \\
0,00\end{array}$ \\
\hline 8 & 24,0 & 59,8 & 72 & $\begin{array}{c}11,15 \pm \\
0,07\end{array}$ & $\begin{array}{c}2,69 \pm \\
0,06\end{array}$ \\
\hline 9 & 0,0 & 37,5 & 48 & $\begin{array}{c}1,80 \pm \\
0,00\end{array}$ & $\begin{array}{c}4,17 \pm \\
0,04\end{array}$ \\
\hline 10 & 30,0 & 37,5 & 48 & $\begin{array}{c}15,00 \pm \\
0,00\end{array}$ & $\begin{array}{c}2,66 \pm \\
0,04\end{array}$ \\
\hline 11 & 15,0 & 0,0 & 48 & $\begin{array}{c}6,49 \pm \\
0,45\end{array}$ & $\begin{array}{c}2,83 \pm \\
0,01\end{array}$ \\
\hline 12 & 15,0 & 75,0 & 48 & $\begin{array}{c}6,70 \pm \\
0,00\end{array}$ & $\begin{array}{c}2,93 \pm \\
0,00\end{array}$ \\
\hline 13 & 15,0 & 37,5 & 7,68 & $\begin{array}{c}4,85 \pm \\
0,07\end{array}$ & $\begin{array}{c}3,05 \pm \\
0,04\end{array}$ \\
\hline 14 & 15,0 & 37,5 & 88,32 & $\begin{array}{c}6,50 \pm \\
0,00\end{array}$ & $\begin{array}{c}2,85 \pm \\
0,07\end{array}$ \\
\hline 15 & 15,0 & 37,5 & 48 & $\begin{array}{c}6,10 \pm \\
0,14\end{array}$ & $\begin{array}{c}2,95 \pm \\
0,05\end{array}$ \\
\hline 16 & 15,0 & 37,5 & 48 & $\begin{array}{c}7,05 \pm \\
0,07\end{array}$ & $\begin{array}{c}2,85 \pm \\
0,00\end{array}$ \\
\hline 17 & 15,0 & 37,5 & 48 & $\begin{array}{c}7,35 \pm \\
0,07\end{array}$ & $\begin{array}{c}2,84 \pm \\
0,02\end{array}$ \\
\hline 18 & 15,0 & 37,5 & 48 & $\begin{array}{c}7,05 \pm \\
0,07\end{array}$ & $\begin{array}{c}2,86 \pm \\
0,01\end{array}$ \\
\hline 19 & 15,0 & 37,5 & 48 & $\begin{array}{c}6,75 \pm \\
0,35\end{array}$ & $\begin{array}{c}2,85 \pm \\
0,01\end{array}$ \\
\hline
\end{tabular}


O volume de ácido lático aplicado foi diretamente proporcional à acidez do polvilho. Em relação à massa de inóculo, observou-se que, na região do gráfico para valores de ácido lático até $8 \mathrm{~mL}$, aumentando a massa de inóculo, ocorreu o aumento na acidez do polvilho. Provavelmente, este efeito deve-se à aceleração da fermentação com acréscimo do inóculo e consequente produção de ácidos orgânicos que provocariam o aumento da acidez titulável. Na região entre 8 - 13 $\mathrm{mL}$ de ácido lático, a massa de inóculo não afetou a acidez titulável do polvilho. Enquanto, na região acima de $13 \mathrm{~mL}$ de ácido lático, o aumento da massa de inóculo resultou na redução da acidez do polvilho. Provavelmente, ocorreu maior adição de ácido lático que provocou o desfavorecimento da microbiota, responsável pela fermentação, propiciando uma inibição da fermentação e a redução da acidez.

Carvalho et al. (34) afirmam que 80,6 \% dos microorganismos responsáveis pela fermentação do polvilho são bactérias ácido láticas (BAL), que a fermentação é realizada por microbiota mista, o que produz aumento da acidez titulável e também que a presença de leveduras seria de vital importância para o fornecimento de açúcares fermentáveis para a atuação das outras bactérias do processo.

A grande variação na acidez titulável dos polvilhos de mandioca é atribuída ao fato de as fermentações não serem submetidas às análises de controle, sendo interrompidas em diferentes estágios de desenvolvimento e de produção dos ácidos $(35 ; 36 ; 37)$. Segundo Cereda (38), essas variações se devem não somente ao teor de ácidos formados, mas também à natureza desses ácidos. Neste trabalho, a variação de acidez, no entanto se dá provavelmente pela quantidade distinta de ácido utilizada em cada experimento, uma vez que o tempo de fermentação não sofreu grandes variações.

Dias (39) concluiu que os amidos tratados com ácidos butíricos, acético ou propiônico tiveram sua acidez titulável reduzida por ocasião da secagem solar, evidenciando a possível evaporação ou destruição destes ácidos, o que não ocorreu com os amidos tratados com o ácido lático, que mantiveram valores altos de acidez após a secagem.

Considerando que o ácido lático não evapora após a secagem e o limite estabelecido na legislação brasileira de $5 \mathrm{~mL}$ de NAOH $1 \mathrm{~N}(100 \mathrm{~g})-1$ para acidez titulável ,tem-se que os valores de acidez encontrados para os polvilhos experimentais da região de máxima expansão (experimentos 15 a 19) são superiores aos permitidos. Tal fato nos remete à necessidade de utilização de quantidades de ácido lático mínimas, considerando a faixa de variação de 10,8 - 21,3 mL sinalizadas na otimização.

A análise de variância para $\mathrm{pH}$ mostrou que o modelo matemático completo foi significativo $(\mathrm{P}=0,0073)$ e a falta de ajuste também ( $\mathrm{FA}=0.0028)$, com coeficiente de variação baixo $(6,24)$ e $85,42 \%$ das respostas foram explicadas pelo modelo completo, sendo reduzido para $81,00 \%$ no modelo ajustado. Assim, o modelo não pode ser considerado preditivo, apenas para visualizar a tendência da resposta. $\mathrm{O}$ efeito linear e quadrático do volume de ácido lático foram significativos para o $\mathrm{pH}$ dos polvilhos de mandioca $(\mathrm{P}=0,000001 ; \mathrm{P}=0,001223$, respectivamente) e o gráfico que ilustra o modelo ajustado é apresentado na Figura 6.

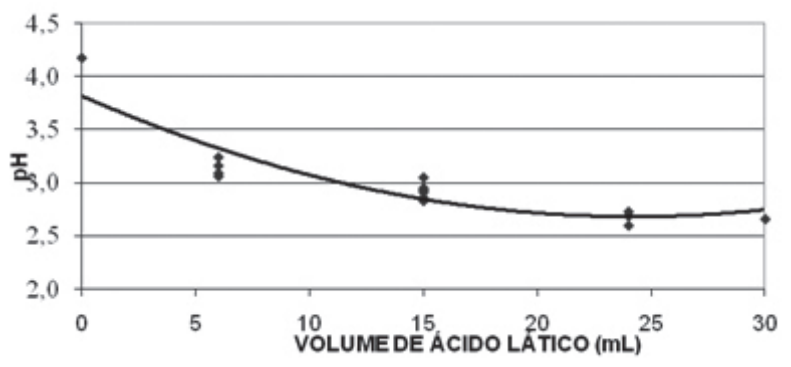

Figura 6. pH dos polvilhos de mandioca em função do volume de ácido lático $(\mathrm{mL})$.

Com o aumento do volume de ácido lático, ocorreu a diminuição do $\mathrm{pH}$ tendendo para estabilização a partir de $25 \mathrm{~mL}$ de ácido lático.

Segundo Dias et al. (40), o acompanhamento do processo de produção do polvilho indicou intensa redução do $\mathrm{pH}$ nos primeiros dias de fermentação, com reduções menos intensas até estabilização, no final da fermentação. Este comportamento foi semelhante ao observado por Cereda e Lima (35), Cereda (38), Cereda e Giaj-Levra (36), Aschieri e Vilela (37), Carvalho et al. (34) e Pereira 
et al. (15), afirmam que a queda do pH ocorre em função da formação de compostos aromáticos e, principalmente, ácidos orgânicos. Entretanto, os autores estudaram tempos de fermentação muito maiores, de 30-60 d, do que os estudados neste trabalho.

Marcon (3) encontrou valores de $\mathrm{pH}$ 3,77; 3,87 e 4,27 para polvilhos azedos de diferentes regiões polvilheiras de Santa Catarina e para polvilhos fermentados em laboratório valores de 3,77 a 4,58.

Tanto os resultados apresentados no presente trabalho quanto nos publicados sobre o $\mathrm{pH}$ de amidos nativos de mandioca revelam uma grande variação neste parâmetro. Vários autores afirmam que o $\mathrm{pH}$ de polvilho azedo é baixo $(41 ; 37 ; 28 ; 34 ; 15 ; 42 ; 43 ; 6 ; 3 ; 44 ; 9)$, o que foi comprovado pelos resultados obtidos neste trabalho que obteve valores de 2,6 a 4,1 .

\section{PROPRIEDADES DE PASTA DOS POLVILHOS ARTEZANAL E EXPERIMENTAL SELECIONADO E DA FÉCULA DE MANDIOCA}

A análise de RVA é uma ferramenta importante no estudo da viscosidade de produtos fonte de amido. Essa análise gera informações importantes, relacionando aspectos de viscosidade durante o aquecimento e resfriamento sobre agitação. As diferenças de viscosidade entre o polvilho artesanal, o polvilho experimental (experimento 18) e fécula de mandioca (sem fermentação) estão ilustradas na Figura 7.

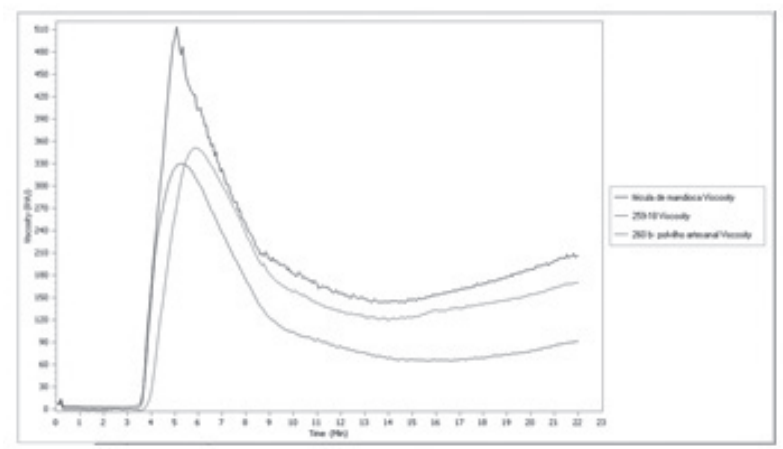

Figura 7. Amilogramas da fécula de mandioca, polvilho artesanal e polvilho do experimento 18 .
Observou-se que a fécula apresentou maior pico de viscosidade, comparativamente ao polvilho azedo, o mesmo foi observado por outros autores $(2 ; 9)$.

Os polvilhos apresentaram valores de viscosidade de pasta menores do que a da fécula de mandioca. Isto porque o amido irradiado com UV sofre mudanças nas propriedades funcionais com aumento da capacidade de ligação de água e da solubilidade e diminuição do pico de viscosidade, o que pode ser observado após exposição à luz solar, particularmente com fécula de mandioca que foi previamente acidificada $(45 ; 46 ; 28)$. A viscosidade das pastas de amidos nativos de diferentes fontes é maior se comparada com a dos amidos que sofreram processo de modificação por agentes oxidantes. Isto se deve ao fato da oxidação reduzir o tamanho das cadeias que compõem o amido (47). A fécula de mandioca tem menor liberação de água que o polvilho azedo, reafirmando a despolimerização do amido durante o processo fermentativo. A quebra das cadeias seria responsável pela menor capacidade do polvilho azedo reter a água; portanto, fécula e polvilho azedo são produtos diferenciados quanto à funcionalidade (2).

\section{COMPOSIÇÃO CENTESIMAL}

Os resultados da composição centesimal para polvilhos de mandioca obtidos nos experimentos estão apresentados na Tabela 8 .

A umidade e as cinzas no polvilho de mandioca são úteis para controlar as condições de secagem e a presença de resíduos de solo no processamento do amido. Os valores obtidos estão em conformidade com a legislação, de acordo com a RDC n ${ }^{\circ} 263$ de 22 de setembro de 2005, o valor de umidade do polvilho deve ser de no máximo $18 \mathrm{~g}$ (100 g)-1 e o de cinzas de $0,50 \mathrm{~g}(100 \mathrm{~g})-1$ (26).

Observa-se uma diferença significativa entre as amostras em relação à umidade, em que a amostra do experimento 5 diferiu das demais e apresentou o maior valor de umidade. Isso porque o parâmetro de retirada das amostras do Sol foi o mesmo utilizado pelos produtores artesanais, ou seja, o toque manual, sendo portanto uma medida imprecisa e responsável por essa divergência . 
Tabela 8. Composição centesimal dos polvilhos de mandioca experimentais.

\begin{tabular}{|c|c|c|c|c|c|}
\hline Experimento & Umidade $\mathrm{g}(100 \mathrm{~g})^{-1}$ & Cinzas $g(100 g)^{-1}$ & Proteína $g(100 g)^{-1}$ & Lipídios g $(100 \mathrm{~g})^{-1}$ & Carboidratos g $(100 \mathrm{~g})^{-1}$ \\
\hline 1 & $8,26 \pm 0,087 \mathrm{EF}$ & $0,093 \pm 0,000 \mathrm{BCDEFG}$ & $0,227 \pm 0,000 \mathrm{CDE}$ & $0,209 \pm 0,026 \mathrm{CDEF}$ & $99,472 \pm 0,026 \mathrm{DEF}$ \\
\hline 2 & $13,14 \pm 0,127 \mathrm{~B}$ & $0,092 \pm 0,008 \mathrm{BCDEFG}$ & $0,239 \pm 0,001 \mathrm{~B}$ & $0,294 \pm 0,001 \mathrm{AB}$ & $99,375 \pm 0,006 \mathrm{GHI}$ \\
\hline 3 & $6,88 \pm 0,006 \mathrm{G}$ & $0,105 \pm 0,004 \mathrm{BCDEFG}$ & $0,222 \pm 0,003 \mathrm{DEF}$ & $0,300 \pm 0,011 \mathrm{AB}$ & $99,373 \pm 0,011 \mathrm{GHI}$ \\
\hline 4 & $9,52 \pm 0,255 \mathrm{D}$ & $0,111 \pm 0,000 \mathrm{BCDEFG}$ & $0,228 \pm 0,004 \mathrm{CDE}$ & $0,291 \pm 0,014 \mathrm{ABC}$ & $99,371 \pm 0,018 \mathrm{GHI}$ \\
\hline 5 & $16,17 \pm 0,254 \mathrm{~A}$ & $0,170 \pm 0,004 \mathrm{~A}$ & $0,248 \pm 0,000 \mathrm{~A}$ & $0,276 \pm 0,041 \mathrm{ABCD}$ & $99,361 \pm 0,037 \mathrm{HI}$ \\
\hline 6 & $4,95 \pm 0,270 \mathrm{H}$ & $0.098 \pm 0,011 \mathrm{BCDEFG}$ & $0,218 \pm 0,004 \mathrm{FGH}$ & $0,269 \pm 0,025 \mathrm{ABCD}$ & $99,417 \pm 0,011 \mathrm{FGHI}$ \\
\hline 7 & $6,87 \pm 0,743 \mathrm{G}$ & $0,129 \pm 0,016 \mathrm{ABCD}$ & $0,222 \pm 0,003 \mathrm{DEF}$ & $0,307 \pm 0,023 \mathrm{~A}$ & $99,347 \pm 0,010 \mathrm{I}$ \\
\hline 8 & $5,23 \pm 0,214 \mathrm{H}$ & $0,087 \pm 0,004 \mathrm{EFG}$ & $0,222 \pm 0,001 \mathrm{DEF}$ & $0,125 \pm 0,012 \mathrm{G}$ & $99,567 \pm 0,007 \mathrm{~A}$ \\
\hline 9 & $7,72 \pm 0,137 \mathrm{FG}$ & $0,095 \pm 0,003 \mathrm{BCDEFG}$ & $0,227 \pm 0,001 \mathrm{CDE}$ & $0,224 \pm 0,001 \mathrm{BCDEF}$ & $99,455 \pm 0,005 \mathrm{DEF}$ \\
\hline 10 & $4,93 \pm 0,302 \mathrm{H}$ & $0,089 \pm 0,007 \mathrm{DEFG}$ & $0,219 \pm 0,000 \mathrm{FGH}$ & $0,219 \pm 0,001 \mathrm{BCDEF}$ & $99,473 \pm 0,007 \mathrm{DEF}$ \\
\hline 11 & $5,48 \pm 0,028 \mathrm{H}$ & $0,095 \pm 0,000 \mathrm{BCDEFG}$ & $0,220 \pm 0,000 \mathrm{EFG}$ & $0,240 \pm 0,007 \mathrm{ABCDE}$ & $99,445 \pm 0,007 \mathrm{DEFG}$ \\
\hline 12 & $5,55 \pm 0,101 \mathrm{H}$ & $0,079 \pm 0,000 \mathrm{G}$ & $0,221 \pm 0,001 \mathrm{DEF}$ & $0,149 \pm 0,020 \mathrm{GF}$ & $99,552 \pm 0,019 \mathrm{ABC}$ \\
\hline 13 & $1,98 \pm 0,064 \mathrm{~J}$ & $0,082 \pm 0,007 \mathrm{FG}$ & $0,211 \pm 0,001 \mathrm{H}$ & $0,233 \pm 0,016 \mathrm{ABCDE}$ & $99,474 \pm 0,024 \mathrm{CDEF}$ \\
\hline 14 & $3,76 \pm 0,234 \mathrm{I}$ & $0,085 \pm 0,004 \mathrm{EFG}$ & $0,213 \pm 0,000 \mathrm{GH}$ & $0,148 \pm 0,001 \mathrm{GF}$ & $99,555 \pm 0,003 \mathrm{AB}$ \\
\hline 15 & $10,99 \pm 0,045 \mathrm{C}$ & $0,13 \pm 0,004 \mathrm{AB}$ & $0,235 \pm 0,002 \mathrm{BC}$ & $0,202 \pm 0,011 \mathrm{DEFG}$ & $99,432 \pm 0,017 \mathrm{EFGH}$ \\
\hline 16 & $9,13 \pm 0,144 \mathrm{DE}$ & $0,121 \pm 0,001 \mathrm{BCDEF}$ & $0,228 \pm 0,000 \mathrm{CD}$ & $0,279 \pm 0,046 \mathrm{ABCD}$ & $99,373 \pm 0,046 \mathrm{GHI}$ \\
\hline 17 & $11,86 \pm 0,056 \mathrm{C}$ & $0,125 \pm 0,000 \mathrm{ABCDE}$ & $0,233 \pm 0,001 \mathrm{BC}$ & $0,165 \pm 0,003 \mathrm{EFG}$ & $99,483 \pm 0,003 \mathrm{BCDEF}$ \\
\hline 18 & $11,78 \pm 0,338 \mathrm{C}$ & $0,131 \pm 0,007 \mathrm{ABC}$ & $0,223 \pm 0,002 \mathrm{DEF}$ & $0,147 \pm 0,011 \mathrm{GF}$ & $99,499 \pm 0,016 \mathrm{ABCDE}$ \\
\hline 19 & $9,42 \pm 0,035 \mathrm{D}$ & $0,091 \pm 0,011 \mathrm{CDEFG}$ & $0,228 \pm 0,002 \mathrm{CD}$ & $0,164 \pm 0,015 \mathrm{EFG}$ & $99,518 \pm 0,006 \mathrm{ABCD}$ \\
\hline
\end{tabular}

${ }^{1}$ Valores apresentados em base seca, exceto para teor de umidade;

Letras maiúsculas diferentes na mesma coluna para cada constituinte se diferem significativamente $(\mathrm{P} \leq 0,05)$ pelo teste Tukey.

Quando se observa o valor de cinzas, encontrado nas amostras de polvilho, verifica-se que as amostras dos experimentos de 1 a 4, 6, 9, 11 e 16 não apresentaram diferenças significativas $(\mathrm{P}>0,05)$ entre si, porém diferem-se da amostra 5 de maior valor $(\mathrm{P} \leq 0,05)$. A elevação do teor de cinzas do polvilho azedo deve-se ao processo de secagem ao Sol, ao ar livre, o qual sofre a ação dos ventos e de poeira.

Quando se compara a composição química da fécula de mandioca com a do polvilho, percebe-se que a fermentação enriquece o teor proteico do polvilho azedo em cerca de dez vezes. Cereda (41), Ascheri e Vilela (37), Plata Oviedo e Camargo (28) afirmam que esse fenômeno ocorre devido aos resíduos metabólicos produzidos por micro-organismos durante a fermentação. Neste trabalho, não houve um enriquecimento tão acentuado, mas houve um aumento do teor proteico. Os valores de proteína encontrados nos polvilhos dos experimentos
$3,7,8,12$ e 18 não diferiram entre si $(\mathrm{P}>0,05)$, sendo todos superiores a $0,2 \mathrm{~g}(100 \mathrm{~g})-1$. NAKAMURA (48), ASCHERI e VILELA (37) citam valores de proteína nos polvilhos azedo de 0,60 a $1,83 \mathrm{~g}$ (100 g)-1, sendo superiores a $0,1 \mathrm{~g}(100 \mathrm{~g})-1$ na maioria destes.

Quanto ao teor de lipídeos, as amostras de polvilho de mandioca experimentais 5, 6 e 16 apresentaram diferenças significativas $(\mathrm{P} \leq 0,05)$, com relação às amostras 8, 12, 14 e 18. Os valores, entretanto, são maiores do que os encontrados por ASCHERI e VILELA (37) que obtiveram 0,006 g (100 g)-1 de lipídeo como teor máximo. Já Marcon et.al. (9) encontrou uma faixa de variação de 0,16 - 0,22 g (100 g)-1 para o teor de lipídeos, próxima a encontrada neste trabalho.

Considerando os valores de carboidratos encontrados, temos que a amostra do experimento 8 diferiu das demais apresentando o maior valor, as amostras dos experimentos 2, 3, 4, 6 e 16 não diferiram entre si $(\mathrm{P}>0,05)$. 


\section{CONTAGEM TOTAL DE MESÓFILOS E DE BOLORES E LEVEDURAS}

A Tabela 9 apresenta os valores encontrados para as análises microbiológicas de Contagem Total de Mesófilos e Bolores e Levedura para os polvilhos experimentais.

Tabela 9. Contagem total de mesófilos e de bolores e leveduras dos polvilhos experimentais.

\begin{tabular}{|c|c|c|}
\hline Experimentos & $\begin{array}{c}\text { Mesófilos } \\
\text { (UFC g-1) }\end{array}$ & $\begin{array}{c}\text { Bolores e } \\
\text { Leveduras } \\
\text { (UFC g-1) }\end{array}$ \\
\hline 1 & $4,3 \times 104$ & $<1,5 \times 102$ \\
\hline 2 & $2,5 \times 104$ & $<1,5 \times 102$ \\
\hline 3 & $2,5 \times 104$ & $<1,5 \times 102$ \\
\hline 4 & $2,5 \times 104$ & $<1,5 \times 102$ \\
\hline 5 & $2,5 \times 104$ & $<1,5 \times 102$ \\
\hline 6 & $2,5 \times 104$ & $<1,5 \times 102$ \\
\hline 7 & $2,5 \times 104$ & $<1,5 \times 102$ \\
\hline 8 & $2,5 \times 104$ & $<1,5 \times 102$ \\
\hline 9 & $2,5 \times 104$ & $<1,5 \times 102$ \\
\hline 10 & $8,8 \times 104$ & $<1,5 \times 102$ \\
\hline 11 & $3,0 \times 102$ & $<1,5 \times 102$ \\
\hline 12 & $3,5 \times 104$ & $<1,5 \times 102$ \\
\hline 13 & $2,5 \times 104$ & $<1,5 \times 102$ \\
\hline 14 & $3,9 \times 104$ & $<1,5 \times 102$ \\
\hline 15 & $3,1 \times 104$ & $<1,5 \times 102$ \\
\hline 16 & $2,5 \times 104$ & $<1,5 \times 102$ \\
\hline 17 & $2,5 \times 104$ & $<1,5 \times 102$ \\
\hline 18 & $7,5 \times 104$ & $<1,5 \times 102$ \\
\hline 19 & $4,1 \times 104$ & $<1,5 \times 102$ \\
\hline
\end{tabular}

Observou-se que as amostras apresentaram a mesma contagem para bolores e leveduras, menor ou igual a $1,5 \mathrm{x}$ 102 UFC g-1, portanto atenderam à legislação brasileira, que prevê contagem máxima de 103 UFC g-1 para esta análise. Com relação à contagem de bactérias mesófilas dos polvilhos experimentais, observou-se contagem na faixa de 3 x 102 a 8,8 x 104 UFC g-1, sendo que 11 das 19 amostras experimentais apresentaram contagem de 2,5 x 104 UFC g-1. Considerando o padrão da legislação de 5 x 105 UFC g-1 ,todas as amostras encontravam-se dentro da faixa permitida.
Cereda e Vilpoux (2003) publicaram variações de 1,2 a 3,6 x 102 UFC g-1 para bolores e leveduras em amostras de polvilho azedo e de 10 a 3,1 x 103 UFC g-1 para contagem total de mesófilos, valores inferiores aos encontrados neste trabalho. As diferenças apontadas se devem provavelmente aos diferentes estágios de fermentação das amostras. Neste trabalho, o tempo de fermentação variou de 7,68 a $88,32 \mathrm{~h}$, o que permite considerar que a contagem de mesófilos está sendo incrementada pelas bactérias láticas na primeira fase da fermentação, uma vez que a fermentação foi interrompida nesta fase, não sendo atingida a fase de decréscimo das bactérias láticas. Tal fato explicaria os valores contagem de mesofilos superiores aos encontrados nos polvilhos artesanais (com fermentação média de 60 d).

\section{MICROSCOPIA ELETRÔNICA DE VARREDURA}

A Figura 8 ilustra a microscopia eletrônica de varredura em diferentes aumentos da fécula de mandioca. Observou-se a forma ovalada predominante e superfície lisa dos grânulos de amido. Enquanto que nos polvilhos azedo artesanal e experimental (experimento 18) (Figura 9) observaram-se superfícies porosas e presença de orifícios e rachaduras típicas do amido que sofreu processo de fermentação.

Os grânulos de fécula de mandioca assim como dos polvilhos azedos observados através da microscopia eletrônica de varredura mostraram formas predominantemente ovaladas, arredondadas e truncadas, típicas de amido de mandioca, com diâmetros variados, que não sofreram mudanças durante a fermentação (Figuras 8 e 9).

Diferentemente das féculas de mandioca, os grânulos dos polvilhos azedos, apresentam perfurações devido à ação de enzimas amilolíticas. Estas atuam primeiramente sobre as zonas amorfas dos grânulos colocados em excesso de água no processo fermentativo (43).

O aspecto alterado da superfície dos grânulos de amido de mandioca, após a fermentação, com perfurações e rachaduras, comprova o efeito do ataque das amilases $(32 ; 3)$. O mesmo efeito foi observado no polvilho artesanal e nos experimentais, não sendo observadas diferenças microscópicas entre eles. 

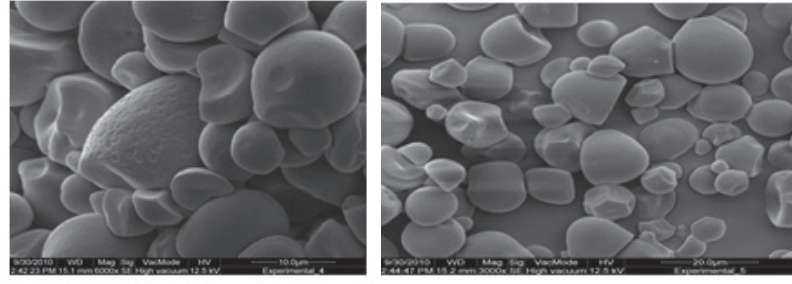

Figura 8. Micrografias eletrônicas de varredura de grânulos de amido de mandioca nativo (fécula).

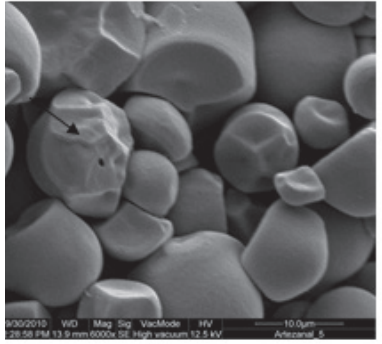

(a)

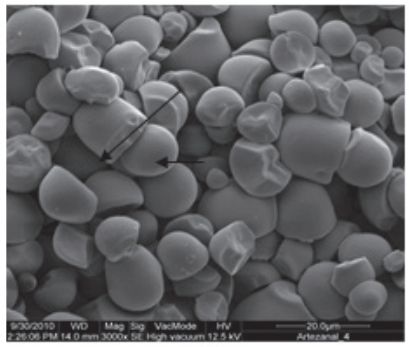

(b)
Figura 9. Micrografias eletrônicas de varredura de grânulos de amido fermentado do polvilho azedo (a) experimental e polvilho artesanal (b).

\section{Conclusão}

O diagnóstico da qualidade do polvilho indicou não haver padrão de qualidade para o produto, pois verificou presença de casca e insetos em todas as amostras analisadas. Quanto à acidez, 12,5\% das amostras não se encontravam dentro dos padrões estabelecidos pela legislação, para as demais análises, os resultados estão em conformidade.

Os padrões físico-químicos e microbiológicos, encontrados para a amostra de fécula utilizada nos ensaios, estão de acordo com a legislação brasileira vigente e com a literatura.

Os resultados da otimização do processo indicaram que a região de máxima expansão $(2,0)$ ocorreu quando o intervalo de variação para o volume de ácido lático foi de 10,8 - 21,3 mL e de 36,0 - 65,3 h para o tempo de fermentação, quando a massa de inóculo foi de $37,5 \mathrm{~g}$.

O índice de expansão alcançado com o polvilho experimental foi superior ao alcançado com a fécula de mandioca e com o polvilho artesanal de maior expansão, detectado no diagnóstico.

A produção de polvilho azedo experimental, a partir de fécula de mandioca, utilizando o método de fermentação rápida e acidificação (da região de máxima expansão) apresentou valor de acidez superior ao permitido pela legislação, em relação ao $\mathrm{pH}$ os valores encontrados para os polvilhos experimentais são coincidentes com a literatura. A viscosidade de pasta do polvilho azedo experimental foi inferior a do polvilho artesanal, não comprometendo a expansão, sendo que essa não esteve diretamente relacionada à viscosidade.

Os polvilhos azedos experimentais atenderam aos padrões microbiológicos vigentes para a contagem total de mesófilos e bolores e leveduras. Atenderam também aos limites previstos na legislação para umidade e cinzas. Os polvilhos azedos, experimental e artesanal apresentaram predominantemente formas esféricas, reniformes e perfurações, quando da observação pela microscopia eletrônica de varredura.

Finalmente, pode-se dizer que a produtividade industrial pode ser incrementada pela redução do tempo médio de fermentação utilizado $(45 \mathrm{~d})$ para o proposto de (48h) utilizando a acidificação e a adição de inóculo.

\section{Referências}

1. Instituto Brasileiro de Geografia e Estatistica-Ibge. Estatística da Produção Agrícola. Maio: 2009.

2. Aplevicz, K. S.; Demiate, I. M. Ciência e Tecnologia de Alimentos, Campinas, 2007, 478-484.

3. Marcon, M. J. A. Efeito do processo fermentativo pelo método tradicional e com adição de glicose, sobre a qualidade do polvilho azedo. 2004. Dissertação (Mestrado em Ciência dos Alimentos) - Universidade Federal de Santa Catarina-UFSC.

4. Gameiro, A. H.; Cardoso, C. E. L. Embrapa Informação Tecnológica, 2003.

5. Leonel, M.; Cereda, M. P. Ciência e Tecnologia de Alimentos, 2002, 65-69.

6. Silveira, I. A; Carvalho, E. P; Schwan, R. F.; Pilon, L. Higiene Alimentar, 2000, 26-31.

7. Lima J. W. C. Análise ambiental: processo produtivo de polvilho em indústrias do extremo sul de Santa Catarina. 2001. Dissertação (Mestrado em Engenharia de Produção) Universidade Federal de Santa Catarina, Santa Catarina. 
8. Cereda, M. P.; Vilpoux O. Cultura de Tuberosas Amiláceas Latino Americanas, 2002, 449-503.

9. Marcon, M. J. A.; Vieira, G. C. N.; Simas, K. N.; Santos, K.; Vieira, M. A.; Castanho, R. D. M.; Amante, E. R. Brazilian Archives Biology and Technology, 2007, 1073-1081.

10. Garcia, A. C. D. B.; Leonel, M. Ciência Agro técnica, 2005, 629-634.

11. Haguete, T. M. F. Metodologias qualitativas na sociologia. 2000.

12. Rickard, J. E.; Behn, K. R. Journal of the Science of Food and Agriculture, 1987, 373-9.

13. Instituto Adolfo Lutz. Normas analíticas do Instituto Adolfo Lutz: métodos químicos e físicos para análise de alimentos. 1985.

14. Cereda, M. P. Boletim da Sociedade Brasileira de Ciência e Tecnologia de Alimentos. 1983, 305-320.

15. Pereira, j. Ciacco; c. F.; vilela, e. R.; texeira, L. S. Ciência e Tecnologia de Alimentos. 1999, 287-293.

16. APHA - American Public Health Association. Compendium of methods for the microbiological of foods. 1992.

17. AACC - AMERICAN ASSOCIATION OF CEREAL CHEMISTS. Approved Methods of the AACC. 1995.

18. AOAC - ASSOCIATION OF OFFICIAL ANALYTICAL CHEMISTS. Official methods of analysis of AOAC International. 1997, v.1 e v.2.

19. Plata Oviedo, M. Secagem do amido fermentado de mandioca: modificação química relacionada com a propriedade de expansão e características físico-químicas. 1998.

20. Maeda, K. C.; Cereda, M. P. Ciência e Tecnologia de Alimentos, 2001, 139-143.

21. Statistica for Windows (2008) Software.Version 7.

22. Pimentel Gomes, F. Curso de estatística experimental. 1990, 467.

23. The Sas System for Windows 3.95 - Release 6.08. SAS Institute, Inc. 1992.

24. Marcon, M. J. A. Proposta para o mecanismo de expansão do polvilho azedo com base nas características físico químicas. 2009.

25. Brasil. Ministério da Saúde. Resolução n ${ }^{\circ}$ 12, de Julho de 1978. Diário Oficial da União, 1978, 23-24.

26. Brasil. Ministério da Saúde. Resolução ${ }^{\circ}$. 263, de Setembro de. Diário Oficial da União, 2005, 368-369.

27. Cavallet, L. E.; Ferreira, S. M. R; Lima, J. J.; Tullio, L. T.; Quadros, D. A. Ciência e Tecnologia de Alimentos, 2006, 522-526.

28. Plata Oviedo, M.; Camargo, C. R. O. Ciência e Tecnologia de Alimentos, 1995, 59-65.
29. CavalleT, L. E. Investigação do processo de fixação biológica de $\mathrm{n} 2$ atmosférico na fermentação de fécula de mandioca. 2002.79 f Tese (Doutorado em Agronomia) - Faculdade de Ciências Médicas e Biológicas de Botucatu.

30. Takizawa, F. F.; Silva, G. O.; Konkel, F. E.; Demiate, I. M. Brazilian Archives of Biology and Technology, 2004, 921-931.

31. Leonel, M.; Garcia, A. C. D. B.; REIS, M. M. Brazilian Journal of Food Technology, 2004, 129-137.

32. Cereda, M. P.; Nunes, O. L. G. S.; Westby, A. Science, 1995, 43-49.

33. Sarmento, S. B. S. Caracterização da fécula de mandioca (Manihot esculenta Crantz) no período de colheita de cultivares de uso industrial. São Paulo, 1997. 162f. Tese (Doutorado em Bromatologia), Faculdade de Ciências Farmacêuticas.

34. Carvalho, E. P.; Canhos, V. P.; Ribeiro, V. E.; Carvalho, H. P. Pesquisa Agropecuária Brasileira, 1996, 129-137.

35. Cereda, M. P.; Lima, U. A. Boletim da Sociedade Brasileira de Ciências e Tecnologia, 1981, 107 - 122.

36. Cereda, M. P.; Giaj-Levra, L. A. Revista Brasileira de mandioca, 1987, 29-33.

37. Ascheri, D. P. R.; Vilela, E. R. Pesquisa Agropecuária Brasileira, 1995, 269-279.

38. Cereda, M. P. Boletim da Sociedade Brasileira de Ciência e Tecnologia de Alimentos. 1983, 297 - 304.

39. Dias, A. R. G. Efeito de oxidantes, de ácidos orgânicos e da fração solúvel em água na propriedade de expansão do amido de mandioca fermentado. 2001, 183f. Tese (Doutorado em Tecnologia de Alimentos.

40. Dias, A. R. G.; Elias, M. C.; Oliveira, M.; Helbig. E. Ciência e Tecnologia de Alimentos, 2007, 794-799.

41. Cereda, M. P. Tecnologia e qualidade do polvilho azedo. Informe Agropecuário, 1987, 63-68.

42. Demiate, I. M.; Barana, A. C.; Cereda, M. P.; Wosiaorg, M. P. Ciência e Tecnologia de Alimentos, 1999, 131-135.

43. Demiate, I. M.; Cereda, M. P. Energia na Agricultura, 2000, 36-46.

44. Marcon, M. J. A.; Vieira, M. A.; Santos, K.; De Simas, K. N.; Castanho, R. D. M.; Amante, E. R. Journal of Food Process Engineering, 2006, 362-372.

45. Mestres, C.; Rouau, X. Journal of the Science of Food and Agriculture. 1997, 147-155.

46. Nunes, O. L. G. S. Efeito da radiação ultravioleta sobre as propriedades funcionais da fécula de mandioca tratada com ácido lático. 1994. Dissertação (Mestrado em Agronomia) Universidade Estadual Paulista.

47. Silva, R. M.; Ferreira, G. F.; Shirai, M. A.; Haas, A.; Scherer, M. L.; Franco, C. M. L Ciência e Tecnologia de Alimentos, 2008, 66-77. 
48. Nakamura, I. M. Contribuição ao estudo da fécula de mandioca fermentada. 1975. Dissertação (Mestrado em Ciência e Tecnologia de Alimentos),. Universidade Estadual de Campinas - UNICAMP.

\section{Christiane A. Starling}

Instituto SENAI de Tecnologia em Alimentos e Bebidas,- Rua Professor Lázaro Costa n ${ }^{\circ}$ 348, Vila Canaã, CEP: 74415-420, Goiânia, Goiás, Brasil.

*E-mail: christianestarling@gmail.com 